\section{Estudo \\ CoDebate}

em Cestão

Plamejamento
Revista Estudo \& Debate, Lajeado, v. 24, n. 2, 2017. ISSN 1983-036X

DOI: http://dx.doi.org/10.22410/issn.1983-036X.v24i2a2017.1194

\title{
SISTEMA DE INDICADORES PARA AVALIAÇÃO DA SUSTENTABILIDADE DE PROPRIEDADES PRODUTORAS DE LEITE
}

\author{
Edson Moacir Ahlert ${ }^{1}$, Claus Haetinger ${ }^{2}$, Claudete Rempel ${ }^{3}$
}

\begin{abstract}
Resumo: $\mathrm{O}$ estudo objetiva apresentar o desenvolvimento de um instrumento para análise, denominado Sistema de Indicadores para Avaliação da Sustentabilidade de Propriedades Produtoras de Leite, visando adequar a sustentabilidade do sistema de produção. O sistema foi desenvolvido em planilha Excel ${ }^{\bullet}$, utilizando um conjunto de 23 indicadores nos aspectos econômicos, sociais e ambientais. Os parâmetros analisados na dimensão econômica foram: Produtividade e renda, diversificação da renda, evolução patrimonial, serviços básicos, escolaridade e capacitação, evolução tecnológica, gestão do empreendimento, sucessão familiar. Para a dimensão social foram avaliados os parâmetros: físicos, psicológicos, sociais, ambientais e de qualidade de vida. Já na dimensão ambiental foram avaliados os parâmetros: dejetos, água, Área de Preservação Permanente, Reserva Legal, agrotóxicos e fertilizantes, declividade, erosão, queimadas, uso da terra. O sistema mostrou-se um método adequado e suficiente para aplicação em campo para avaliaçấo do impacto de atividades agropecuárias.
\end{abstract}

Palavras-chave: Desenvolvimento. Sustentabilidade. Indicadores. Produção leiteira. Ciências Ambientais.

\section{SYSTEM OF INDICATORS FOR EVALUATING THE SUSTAINABILITY OF MILK PRODUCERS FARMS}

\begin{abstract}
This study aims to present the development of an instrument for analysis, called Indicators System for the Evaluation of the Sustainability of Milk Producing Properties, aiming at adapting the sustainability of the production system. The system was developed in an Excel $^{-}$worksheet, using a set of 23 indicators in economic, social and environmental aspects. The parameters analyzed in the economic dimension were: productivity and income, income diversification, patrimonial evolution, basic services, education and training, technological evolution, enterprise management, family succession. For the social dimension the parameters were evaluated: physical, psychological, social, environmental and quality of life. In the environmental dimension, the following parameters were evaluated: waste, water, Permanent Preservation Area, Legal Reserve, pesticides and fertilizers, declivity, erosion, burning, land use. The system proved to be an adequate and sufficient method for field application to evaluate the impact of agricultural activities
\end{abstract}

Keywords: Development. Sustainability. Indicators. Dairy production. Environmental Sciences.

1 Mestre em Ambiente e Desenvolvimento, professor da Univates.

2 Doutor em Matemática, professor da Univates.

3 Doutora em Ecologia, professora da Univates. 


\section{INTRODUÇÁO}

A atividade agropecuária, devido ao elevado potencial de danos que pode causar pode ser, vista como uma das principais vilãs do meio ambiente. Neste aspecto, independente da atividade que desenvolve, do nível tecnológico e de seu tamanho, exige-se que produtores rurais adotem práticas visando não apenas a obtenção de lucros, mas também a utilização planejada dos recursos naturais, acarretando assim o equilíbrio entre a atividade exercida e a conservação do ambiente (RIBEIRO; BRITES; JUNQUEIRA, 2006).

É perceptível que agricultura familiar, e nela situada a produção de leite, possui importância nacional em termos econômicos e sociais, envolvendo contingente significativo de produtores, reduzindo o êxodo rural e diversificando os sistemas de produção, contribuindo para o desenvolvimento dos municípios de pequeno e médio porte. Os empreendimentos rurais possuem um papel importante no cenário econômico regional, necessitando crescer e desenvolver-se de forma sustentável.

Buainain e Romeiro (2000) ressaltam que uma das questóes-chave para o agronegócio é a problemática da sustentabilidade. A predominância da agricultura convencional, e junto a ela a produçâo de leite, executada por produtores familiares, tem comprometido de forma até mesmo irreversível a agricultura, por ocasionar degradação do solo, destruição das matas, perda da biodiversidade, uso indiscriminado de agrotóxicos e de adubos químicos, destruição dos mananciais e tantas outras práticas danosas; e trazido prejuízos incalculáveis à natureza.

Para Rodrigues, Campanhola e Kitamura (2003) o conceito de sustentabilidade está relacionado ao desenvolvimento rural sustentável, e envolve o aumento de produção e renda, implicando numa melhoria generalizada das condiçóes de vida e de trabalho no espaço agrícola, além de gerar simultaneamente impactos positivos para o meio ambiente.

Os produtores rurais, muitas vezes, priorizam aspectos ambientais, adotando práticas direcionadas ao uso correto dos recursos naturais, quando estes interferem diretamente nos resultados econômicos da atividade (RIBEIRO; BRITES; JUNQUEIRA, 2006). Nota-se que tradicionalmente os produtores seguem o conceito de desenvolvimento como sendo apenas o crescimento econômico.

Todavia, a sustentabilidade não deve ser vista somente sob a dimensão ambiental, pois outros aspectos estão relacionados a ela. Também não é possível agir visando apenas a obtenção de retornos financeiros, sem levar em consideração os aspectos social e ambiental, ou seja, buscar o desenvolvimento de negócios e processos que sejam sustentáveis observando estes três aspectos.

A partir do surgimento da concepção de sustentabilidade e com a frequência com que esta passou a ser empregada, assumindo diversas dimensóes e buscando embasar uma nova forma de desenvolvimento, tornou-se necessário definir parâmetros que mensurassem, monitorassem e avaliassem a sustentabilidade. Nasceu, assim, a ideia de indicadores de sustentabilidade, que, por sua vez, trouxe consigo a necessidade de definir padróes sustentáveis de desenvolvimento que considerassem aspectos ambientais, econômicos e sociais (VERONA, 2008). 
Rodrigues, Campanhola e Kitamura (2003) destacam que para fazer a avaliação de desempenho de uma atividade rural, do ponto de vista gerencial, devem-se utilizar medidas e análises de indicadores com foco na sustentabilidade das atividades produtivas, abrangendo suas vertentes econômicas, sociais e ambientais. Estes indicadores são organizados normalmente em sistemas de avaliação, que podem endereçar níveis crescentes de exigências de metas de gestão ambiental e complexidade.

Para Verona (2008), os indicadores desempenham função fundamental na geração de dados para avaliação da sustentabilidade, indicando a direção, a prioridade das mudanças e orientando a caminhos e propostas que possam contribuir com o desenvolvimento sustentável do sistema produtivo.

Um estudo com indicadores não apenas viabiliza a construção de propostas de unidades de produção agrícolas mais adequadas, pela transformação de dados em informaçóes relevantes, mas ainda fornece informaçóes para a construção de estratégias de planejamento e políticas para um desenvolvimento sustentável, conforme apontado por Verona (2008).

Assim, o objetivo deste trabalho é apresentar o desenvolvimento de um instrumento para análise, denominado Sistema de Indicadores para Avaliação da Sustentabilidade de Propriedades Produtoras de Leite, visando adequar a sustentabilidade do sistema de produção.

Como objetivos específicos, acredita-se que a análise da propriedade, em primeiro momento, permitirá: a) auxiliar cada produtor conforme os pontos específicos que merecerem maior atenção ou destacar aqueles que estão adequados; b) caracterizar e validar a estrutura e o funcionamento de uma planilha de significância aplicada ao processo de planejamento sob a perspectiva do desenvolvimento sustentável; c) verificar características gerais das propriedades produtoras de leite, considerando, principalmente, aspectos no âmbito socioeconômico e ambiental; d) determinar a situação ambiental das propriedades e se necessário sugerir mudanças que auxiliem o produtor a tornar a atividade agrária sustentável; e e) oferecer aos produtores e técnicos uma ferramenta de simples operacionalização, com relatórios e gráficos de fácil interpretação.

A vantagem do método proposto em relação aos métodos disponíveis é que este agrega componentes de diferentes naturezas, permitindo a composição de índices parciais de impacto ambiental para cada dimensão - econômica, social e ambiental, e ao mesmo tempo de um índice agregado de avaliação de impacto.

O propósito foi o de construir uma ferramenta de avaliação tão fácil de manusear quanto possível, mas que capte (tanto quanto possível) esta realidade complexa. Almeja-se que o indicador funcione como uma ferramenta primária e genérica, ou seja, que meça os componentes mais relevantes (essenciais) da sustentabilidade no agronegócio - ferramenta primária, e que sua utilização seja possível em vários contextos da produção primária ferramenta genérica. 


\section{REFERENCIAL TEÓRICO}

O referencial teórico que deu subsídios à realização da presente pesquisa está divido em quatro capítulos, abordados de maneira interdisciplinar: Produção Leiteira na Agricultura Familiar; Sustentabilidade e suas Dimensóes; Problemáticas Ambientais e Produção Leiteira; e Avaliação da Sustentabilidade em Agroecossistemas.

\subsection{Produçáo Leiteira na Agricultura Familiar}

A agricultura familiar é a forma predominante de produção agrícola em várias regióes do Brasil, sendo essencial para a economia de vários municípios. Esta é uma opção viável, proporcionando o desenvolvimento sustentável e a geraçáo de emprego e renda no meio rural (SCHNEIDER; NIEDERLE, 2008).

O Censo Agropecuário de 2006 mostra que o Brasil tem mais de 1,3 milhóes de propriedades que exploram a atividade leiteira, ocupando diretamente cerca de 3,6 milhóes de pessoas somente no setor primário, principalmente na agricultura familiar, ou seja, pelos pequenos produtores, que respondem por $81 \%$ dos estabelecimentos e $58 \%$ da produção de leite do país (IBGE, 2006). Ainda segundo este censo, a participação regional na produção de leite brasileira em 2013 foi de $35,1 \%$ no Sudeste; $34,4 \%$ no Sul; $14,6 \%$ no CentroOeste; $10,5 \%$ no Nordeste; e 5,4\% na regiāo Norte. Minas Gerais foi o estado responsável por $28 \%$ da produção nacional de leite, seguido pelo Rio Grande do Sul (13\%), Paraná (12\%) e Goiás (11,0\%).

Yamaguchi, Martins e Oliveira (2005) sustentam que a pecuária de leite é considerada um dos setores mais complexos dentre as atividades agropecuárias, pois envolve tanto atividades pecuárias quanto atividades agrícolas. Noronha e Lima Junior (2005, p. 42), por sua vez, afirmam que "são várias unidades de negócio relacionadas a um grande negócio", por que junto a atividade leiteira também é realizada a criação de animais e seu manejo alimentar, sanitário e reprodutivo, além da produção agrícola para produzir grãos e volumosos (pasto, feno e silagem) para o rebanho.

Segundo Costa e Bueno (2011), para garantir a sustentabilidade na bovinocultura leiteira é necessário, portanto, que esteja amparada por melhorias quanto ao manejo e práticas que contribuam na manutenção e melhorias no contexto socioeconômico e ambiental.

\subsection{Sustentabilidade e suas Dimensóes}

O termo sustentabilidade ou desenvolvimento sustentável popularizou-se a partir de 1987, quando foi adotado na Comissão Mundial sobre Meio Ambiente e Desenvolvimento das Naçóes Unidas, no Relatório Brundtland, conhecido como Nosso Futuro Comum (CMMAD, 1991). Nesse documento, foi cunhada a clássica definição de desenvolvimento sustentável: "aquele que atende às necessidades das geraçóes atuais sem comprometer a capacidade das futuras geraçóes terem suas próprias necessidades atendidas".

A questão ambiental envolve processos naturais e sociais excluídos da racionalidade econômica como a degradação do meio ambiente, a perda da biodiversidade, das tradiçóes culturais e da qualidade de vida. Essa discussão demanda a construção de uma racionalidade 
ambiental com a colaboração de diversas especialidades em uma organização interdisciplinar do conhecimento, exigindo assim uma visão sistêmica e integrada de diversos campos do saber (LEFF, 2010).

Assim, é importante atuação interdisciplinar para prover melhores respostas às questôes relacionadas à sustentabilidade. Neste tocante, Leff (2010) ressalta a preocupação para que a dimensão econômica não seja priorizada perante as demais, pois, para que haja o desenvolvimento, é necessário que este se compatibilize, em equilíbrio com a viabilidade econômica, a qualidade de vida, o bem-estar e a igualdade social das pessoas, e ainda, seja mantida a conservação da produtividade dos recursos naturais.

São várias as dimensôes da sustentabilidade, de acordo com Barbieri e Cajazeira (2009): econômica, social, ecológica, espacial, cultural, política e institucional. Entretanto, os autores asseguram que no âmbito das organizaçóes consideram-se normalmente três dimensóes, que são a econômica, a social e a ambiental. Desta forma, uma organizaçáo sustentável "[...] busca alcançar seus objetivos atendendo simultaneamente os seguintes critérios: equidade social, prudência ecológica e eficiência econômica" (BARBIERI; CAJAZEIRA, 2009, p. 69-70).

Para Sachs (2004), para o desenvolvimento sustentável o crescimento econômico é necessário, mas devem coexistir regras de prudência ecológica no uso dos recursos naturais e principalmente redução das desigualdades sociais. Neste sentido, apesar da importância da problemática ambiental no conceito de desenvolvimento sustentável, o autor salienta a relevância da preocupação social, quando afirma que o ser humano excluído social e economicamente não consegue assumir compromisso com a questáo ambiental, pois se vê à margem de uma sociedade que permite sua deterioração enquanto pessoa.

Ferreira et al. (2011), citando diversos autores, afirmam que, ao se falar em sustentabilidade, devem ser considerados, no mínimo, as dimensóes: econômica, ambiental e social. Estas serão as dimensões enfatizadas neste trabalho, onde procurou-se operacionalizar os conceitos com base na bibliografia, porém direcionados para o contexto local.

Diversos autores compartilham da mesma opinião, destacando serem os fatores econômicos, social e ambiental considerados os mais relevantes para a avaliação da sustentabilidade. Estes aspectos sustentam a teoria de Leff (2010) por colocar uma preocupação para que o desenvolvimento crie um equilíbrio entre a viabilidade econômica, a qualidade de vida, o bem-estar, a igualdade social das pessoas, e ainda a conservação da produtividade dos recursos naturais.

\subsection{Problemáticas Ambientais e Produçáo Leiteira}

Somente na última década as preocupaçóes com os impactos ambientais oriundos de atividades agrícolas assumiram maiores dimensões. Esses impactos podem ser expressos pela contaminação e assoreamento dos mananciais, redução da biodiversidade, entre outros danos ambientais. Os reflexos desta degradação ambiental podem ser demonstrados por meio de variações na produção e produtividade agrícolas e no bem-estar socioeconômico de uma comunidade (MARQUES; SKORUPA; FERRAZ, 2003). 
A bovinocultura leiteira é uma atividade que utiliza os recursos naturais como matéria prima para produção do leite e o manejo inadequado pode prejudicar o solo, contaminar a água e prejudicar a manutenção da biodiversidade, contribuindo para a degradação do ambiente.

A pecuária leiteira é considerada uma das atividades mais complexas dentro de um agroecossistema, pois envolve tanto atividades pecuárias quanto atividades agrícolas (YAMAGUCHI; MARTINS; OLIVEIRA, 2005). Como afirmam Noronha e Lima Junior (2005, p. 42) “[...] são várias unidades de negócio relacionadas a um grande negócio”, uma vez que está incluída no processo de produção do leite também a criação de animais e seu manejo alimentar, sanitário e reprodutivo, além do cultivo agrícola para produzir volumosos e grãos para o rebanho.

Para Rempel et al. (2012), a ausência de práticas ambientais adequadas no manejo das propriedades rurais e da atividade leiteira, especialmente em relação aos dejetos bovinos, resulta em expressivos impactos ao meio ambiente, principalmente sobre a baixa qualidade da água de recursos hídricos superficiais.

\subsection{Avaliaçáo da Sustentabilidade em Agroecossistemas}

Gliessman (2001), frente a necessidade de avaliação de sustentabilidade, evidencia a importância de utilizar ferramentas para análise do agroecossistema, evidenciando seu desempenho e eficiência e os problemas enfrentados. Desse modo, a partir da seleção de um conjunto de indicadores de sustentabilidade, poderão ser apresentadas informaçóes para a tomada de decisões e para monitorar açôes desenvolvidas em unidades de produção rurais.

Para avaliar a sustentabilidade de um sistema de produção é preciso ferramentas capazes de mensurar este conceito. Esta avaliação pode ser realizada por meio do uso de indicadores, que são entendidos como parâmetros, para fornecer informaçóes sobre um fenômeno, uma situação expressiva positiva ou negativamente (BELLEN, 2010), sendo seu objetivo quantificar informaçóes de modo que sua significância fique aparente.

Rodrigues, Campanhola e Kitamura (2003) compartilham da mesma opinião, ao afirmarem que para fazer a avaliação de desempenho de atividades rurais, do ponto de vista gerencial, deve-se fazê-lo por meio de medidas e análises de indicadores com foco na sustentabilidade das atividades produtivas, relacionando suas vertentes econômicas, sociais e ecológicas. De maneira ideal, estes indicadores são organizados em sistemas de avaliação, que podem endereçar níveis de complexidade crescentes e exigências de metas de gestão ambiental.

A definição de indicador é fundamental para a formulação de um conceito para indicador de sustentabilidade. Existem dezenas de definiçóes para o termo indicador, enfocando os objetivos e as características dos mesmos, deixando claro que a sua função está relacionada a medir processos, para comunicar informaçóes a um determinado público. Indicador é, pois, um instrumento que permite a avaliação de um sistema e que determina o nível ou condição em que este deve ser mantido para que seja sustentável (DEPONTI; ECKERT; AZAMBUJA, 2002). 
Diversos autores citam o uso de indicadores de sustentabilidade como um exemplo de estratégia para avaliação de agroecossistemas. Para Verona (2008, p. 42), "um estudo com indicadores náo apenas proporciona a construção de propostas de agroecossistemas mais adequados [...], mas também informaçôes para a construção de estratégias políticas e de planejamento para um desenvolvimento sustentável". Diante do exposto, os indicadores podem informar uma determinada situação, e também passar percepçóes de tendências ou fenômenos não detectados imediatamente.

Um estudo com indicadores, para Verona (2008), não proporciona apenas a construção de propostas de espaços rurais mais adequados, como também fornece informaçóes para estratégias de planejamento em busca do desenvolvimento sustentável, apontando direçóes e as mudanças prioritárias para atingir a sustentabilidade.

Por outro lado, é necessário estabelecer a escala espacial em que se dará a avaliação, pois "os indicadores descrevem um processo específico e são particulares a esses processos, e por isso não há um conjunto de indicadores globais adaptáveis a qualquer realidade" (DEPONTI; ECKERT; AZAMBUJA, 2002, p.51).

Segundo Leff (2010) a avaliação da sustentabilidade deve contemplar indicadores que avaliem além da rentabilidade econômica e a preservação do ambiente, também aspectos sociais e culturais. Considera-se que a degradação ambiental e a pobreza estáo diretamente relacionadas em um círculo perverso, assim indicadores da fertilidade do solo, eficiência energética e de potencial ecológico devem ser analisados em relação as necessidades e a qualidade de vida da população.

Ferreira et al. (2012) sustentam que os indicadores de sustentabilidade devem ser concebidos com vistas à otimizaçáo da relação entre sensibilidade e custo/facilidade de aplicação. Para isso, indicam utilizar indicadores já conhecidos e validados pela literatura, que sejam de baixo custo e fáceis de serem aplicados por técnicos ou produtores sem treinamento especializado. Portanto, os indicadores de sustentabilidade são dinâmicos e variam de acordo com a natureza do objeto de estudo.

Outro aspecto importante ainda é que não existe a possibilidade de se determinar a sustentabilidade de um sistema considerando apenas um indicador, ou indicadores que se refiram a apenas um aspecto do sistema. Observa-se que a sustentabilidade é determinada por um conjunto de fatores ou dimensóes e todos devem ser contemplados. Assim, ao se avaliar a sustentabilidade de um sistema deve-se sempre utilizar um conjunto de indicadores (MARZALL; ALMEIDA, 2000).

\section{PROCEDIMENTOS METODOLÓGICOS}

\subsection{Caracterizaçáo da pesquisa}

Trata-se de um estudo que, de acordo com o modo de abordagem do problema é qualitativo, segundo o objetivo geral é exploratório e descritivo. Utilizou com procedimentos técnicos a pesquisa de campo, o estudo de caso e a pesquisa documental sendo um estudo de corte transversal. 


\subsection{Descrição das escolhas metodológicas}

O sistema de indicadores para avaliação da sustentabilidade aqui proposto dá continuidade à pesquisa desenvolvida por Rempel et al. (2012), que definiu uma abordagem metodológica para a avaliação da sustentabilidade ambiental de propriedades produtoras de leite no Vale do Taquari, Rio Grande do Sul.

Para a construção do sistema foram utilizados indicadores já conhecidos e validados pela literatura, tendo como critério para escolha dos indicadores: que sejam de baixo custo e fáceis de serem aplicados por produtores ou técnicos sem treinamento especializado, sendo desenvolvido baseado nas propostas de WHOQOL (1998), Rodrigues, Campanhola e Kitamura (2003), Verona (2008), Ferreira et al. (2012) e Rempel et al. (2012).

A ferramenta foi desenvolvida em planilha de cálculo Excel ${ }^{\oplus}$, da Microsoft ${ }^{4}$, sendo uma plataforma computacional amplamente disponível, passível de fácil distribuição e uso a baixo custo. A apresentaçáo gráfica dos resultados de performance da atividade para cada indicador oferece um diagnóstico para o produtor/administrador, apresentando a situação em conformidade com padróes de impacto da atividade nas condiçóes do estabelecimento rural, provendo uma medida final integrada.

Foram definidos os indicadores em cada dimensão que ponderaram a sua composição. Partindo-se então das três dimensóes propostas foi realizado um esforço de localização dentro de cada uma delas dos pontos críticos do sistema que interfeririam de forma decisiva para o seu desenvolvimento, realçando assim as suas vulnerabilidades (DEPONTI; ECKERT; AZAMBUJA, 2002).

\subsection{Forma de coleta dos dados e procedimentos técnicos}

Para validação do método, a proposta, que objetivou analisar a perspectiva de desenvolvimento rural sustentável, por meio de um sistema de indicadores para avaliação da sustentabilidade de propriedades produtoras de leite, foi aplicada em cinco propriedades produtoras de leite no município de Teutônia, no Vale do Taquari, Rio Grande do Sul, as quais estão vinculadas à pesquisa denominada "Sustentabilidade ambiental em propriedades produtoras de leite do Vale do Taquari”, do Centro Universitário UNIVATES, que forneceu dados para o desenvolvimento do presente trabalho.

Os procedimentos técnicos utilizados para a construção do sistema de indicadores para avaliação da sustentabilidade de propriedades produtoras de leite tomaram como base as metodologias propostas para avaliação:

- da sustentabilidade ambiental: Rempel et al. (2012), metodologia utilizada para avaliar a sustentabilidade ambiental do Vale do Taquari/RS, e também replicada por Di Domenico et al. (2017) no oeste de Santa Catarina;

- da sustentabilidade social: Organização Mundial da Saúde, para verificação da qualidade de vida: WHOQOL (1998);

4 http://www.microsoft.com 
- da sustentabilidade econômica: Rodrigues, Campanhola e Kitamura (2003) e Verona (2008), Ferreira et al. (2012).

Os indicadores foram identificados e caracterizados a partir da adaptação da metodologia dos autores e foram pautados pelos pressupostos de serem indicadores fáceis de interpretar e que fornecessem a informação necessária para permitir gerar um diagnóstico da perspectiva de sustentabilidade em propriedades produtoras de leite, possibilitando uma visão clara dos pontos frágeis ou entraves à sustentabilidade.

A metodologia de trabalho foi dividida em cinco etapas interdependentes e que sucedem de forma cronológica, conforme descrito no fluxograma abaixo, que apresenta, de forma resumida, as etapas do trabalho (FIGURA 1).

Figura 1 - Fluxograma do desenvolvimento da pesquisa

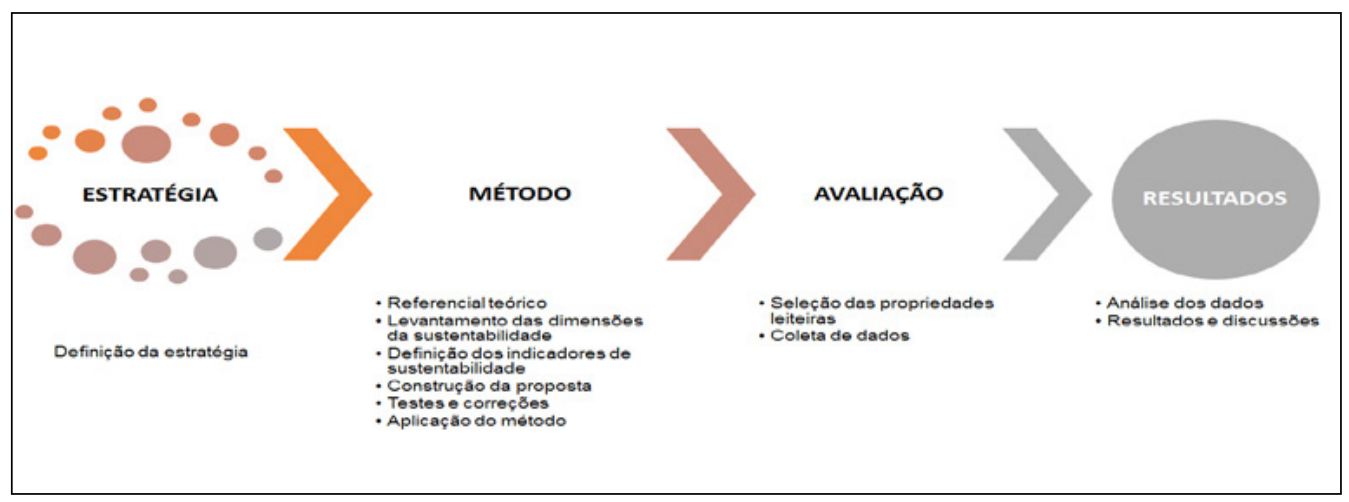

Fonte: Elaborado pelos autores (2016).

A ferramenta Sistema de Indicadores para Avaliação da Sustentabilidade de Propriedades Produtoras de Leite caracteriza-se por ser um sistema integrado para a aferição do desempenho socioeconômico e ambiental das propriedades rurais produtoras de leite, desenvolvida em planilha Excel ${ }^{\circ}$, que permite ao produtor/administrador rural realizar um diagnóstico da situação atual do seu empreendimento, por meio de indicadores de sustentabilidade, e a partir daí definir metas e ações de melhoria do desempenho.

Por meio deste instrumento pode-se estimular a interpretação, a compreensão e a reflexão da realidade do produtor/administrador, sob um olhar sustentável e, sobretudo, motivar os agentes para uma intervenção e transformação, ou seja, um instrumento para facilitar o diálogo em busca de acertos e correçôes no processo, visando adequar a sustentabilidade do sistema de produção.

Com um grupo de indicadores de fácil compreensão e mensuração a avaliação da sustentabilidade permitirá que os produtores visualizem melhor a contribuição das práticas de base ambiental sobre o seu sistema de produção e façam os seus próprios julgamentos sobre os sistemas de manejo e organizaçáo social, buscando melhorar suas práticas e seus comportamentos em busca de uma produção mais sustentável. 
O sistema foi estruturado em cinco planilhas do Excel $^{\circledR}$, abrangendo os balanços econômico, social e ambiental do estabelecimento, além de uma planilha para identificação do produtor e propriedade e a planilha com os relatórios e gráficos de resultados (FIGURA 2).

A utilização de planilhas em Excel $^{\odot}$ permite que a ferramenta seja de simples operacionalização, sendo uma plataforma computacional amplamente disponível, passível de simples distribuiçẫo e uso a baixo custo, e com a aplicação de indicadores já conhecidos e validados pela literatura, torna-o de fácil aplicação pelos produtores, administradores ou técnicos, sem treinamento especializado.

Figura 2 - Sistema de Indicadores para Avaliação da Sustentabilidade

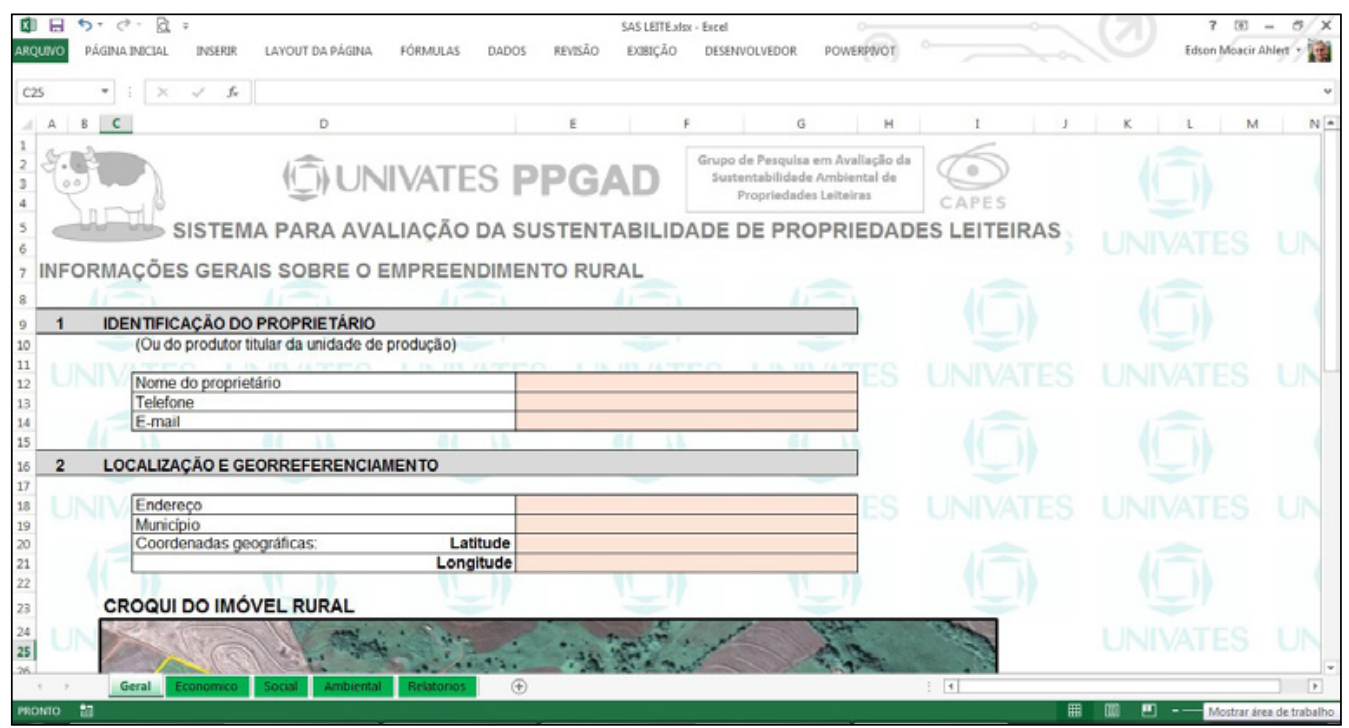

Fonte: Elaborado pelos autores (2016).

A adoção da ferramenta Excel $^{\oplus}$ foi ainda motivada por este tratar-se de um software (programa de computador) extremamente estável, que uma vez que esteja instalado e configurado no computador do usuário, exige pouquíssima ou nenhuma necessidade de manutenção ou suporte. A escolha por uma linguagem de programação para o desenvolvimento da proposta, geraria grandes ônus quanto à necessidade de instalação, configuração, e posterior manutenção e suporte ao sistema.

Nesta ferramenta as informações são preenchidas diretamente na planilha eletrônica, possibilitando a participação do produtor, administrador ou do técnico durante as avaliaçóes. A partir daí o programa calcula e gera os indicadores nas três dimensões e a apresentação gráfica dos resultados de performance da atividade mostra o resultado do diagnóstico para o produtor/administrador, demonstrando a situação e impactos da atividade nas condiçóes do estabelecimento rural, provendo uma medida final integrada.

A grande vantagem do método em relação aos métodos disponíveis é agregar componentes de diferentes naturezas e possibilitar a composição de índices parciais de 
impacto para cada dimensão - econômica, social e ambiental - e ao mesmo tempo de um índice final agregado, sintetizando a série de informações quantitativas.

A primeira etapa consistiu na seleção dos indicadores mais próximos da realidade que se pretendia avaliar. Além das metodologias propostas pelos autores acima mencionados, esta etapa foi realizada junto a dois produtores leiteiros e também surgem a partir das percepçóes, conhecimentos e experiências prévias por parte do pesquisador.

Esta fase, realizada no primeiro semestre de 2015, incluiu diálogos com os produtores, acompanhamento de suas atividades na propriedade, entrevistas relacionadas ao manejo, produção e cuidados ambientais, baseadas nas propostas de Rodrigues, Campanhola e Kitamura (2003) e Verona (2008), Ferreira et al. (2012) e Rempel et al. (2012).

A partir destas atividades e paralelo a estas, foi iniciado construção do protótipo do sistema de indicadores, realizados testes, entre outros, com o objetivo de poder definir os melhores indicadores e estruturá-los num sistema integrado de avaliação.

Além disso foram realizadas reunióes e aplicadas entrevistas com representantes da Secretaria Municipal da Agricultura da cidade de Teutônia, com um diretor de uma agroindústria leiteira também de Teutônia e com um gestor em empreendimentos rurais, sempre com o objetivo de poder detectar quais as principais variáveis que deveriam estar presentes no sistema de indicadores.

Assim, a tentativa de complementar a resposta à questão da pesquisa se deu com um trabalho de campo, que permitiu avaliar os indicadores utilizados, verificar as lacunas, sistematizar aspectos teóricos para a proposição de novos escopos e propor um conjunto de indicadores e validá-los.

Uma vez sistematizados os resultados e concluída a seleção dos indicadores e a construção do sistema de diagnóstico, foi realizado um teste piloto nas duas propriedades que ajudaram na construção do protótipo inicial, com o objetivo de testar e aferir o sistema para aplicação neste trabalho.

Nestes testes foram detectadas algumas deficiências no sistema para a avaliação de algumas variáveis bem como identificadas necessidades de correção nas funçóes para o cálculo da utilidade de alguns indicadores, e após os devidos ajustes foram efetuados no software.

Assim, durante o período de validação inicial (pré-teste) da ferramenta foram incluídos, ajustados e corrigidos indicadores, com o objetivo de captar uma maior quantidade de situaçóes decorrentes das atividades rurais com produção leiteira e que melhor pudessem caracterizar as propriedades e atividades nela realizadas.

Esta etapa ocorreu por meio de um processo sistemático de aplicação e verificação, além de correçóes que se mostraram necessárias durante o processo de validação inicial e, o fechamento ocorreu no momento em que o sistema de avaliação mostrou-se que poderia ser adotado na "vida real".

Salienta-se que este trabalho foi possível também a partir das percepções, conhecimentos e experiências prévias por parte do pesquisador e com base nas informaçóes levantadas junto ao grupo técnico consultado, bem como por meio dos diálogos com os 
produtores; e por fim validado com a aplicação do questionário em cinco propriedades produtoras de leite.

Acrescenta-se ainda que o levantamento e identificação dos indicadores de sustentabilidade, bem como a identificação das questóes referentes ao método e ao manuseio dos indicadores utilizados na avaliação dos agrossistemas para a construção do sistema foi satisfatória e será complementada ao longo do estudo de caso.

A ferramenta consta de um questionário com um conjunto de 23 indicadores de sustentabilidade (distribuídos em cinco planilhas), abrangendo o balanço econômico, social e ambiental do estabelecimento, sendo todos os dados obtidos registrados e processados em uma planilha eletrônica padronizada.

Os parâmetros relacionados com a questão econômica estão descritos na Tabela 1.

Tabela 1 - Parâmetros de avaliação da sustentabilidade econômica

\begin{tabular}{ccccc}
\hline Parâmetro & $\begin{array}{c}\text { Pontuaçáo } \\
\text { máxima } \\
\text { possível }\end{array}$ & Subparâmetro & Pontuaçáo & $\%$ \\
\hline $\begin{array}{c}\text { Produtividade e } \\
\text { renda }\end{array}$ & $\mathbf{2 0}$ & $\begin{array}{c}\text { Relação custo/benefício da atividade } \\
\text { Pretensáo para os próximos anos } \\
\text { Satisfação com a renda }\end{array}$ & 5 & 20 \\
\hline $\begin{array}{c}\text { Diversificaçáo da } \\
\text { renda }\end{array}$ & $\mathbf{1 0}$ & Principais fontes de renda e participação & 10 & 10 \\
\hline Evoluçáo patrimonial & $\mathbf{1 0}$ & Evoluçáo patrimonial do imóvel rural & 10 & 10 \\
\hline $\begin{array}{c}\text { Grau de } \\
\text { endividamento }\end{array}$ & $\mathbf{1 0}$ & Valor da dívida em relaçáa a renda & 10 & 10 \\
\hline $\begin{array}{c}\text { Serviços básicos } \\
\text { Escolaridade e } \\
\text { capacitaçáo }\end{array}$ & $\mathbf{1 0}$ & Acesso a serviços básicos & 10 & 10 \\
\hline Evoluçáo tecnológica & $\mathbf{1 0}$ & Escolaridade e capacitação para a & 10 & 10 \\
\hline $\begin{array}{c}\text { Gestáa do } \\
\text { empreendimentodade }\end{array}$ & $\mathbf{1 0}$ & Evoluçáo tecnológica & 10 & 10 \\
\hline Sucessáo Familiar & $\mathbf{1 0}$ & Gestáo do empreendimento & 10 & 10 \\
\hline Totais & - & Sucessão familiar & 10 & 10 \\
\hline
\end{tabular}

Fonte: Adaptado de Ferreira et al. (2012).

A sustentabilidade social foi avaliada a partir da percepção do produtor/administrador em relação a sua qualidade de vida e foi feita usando a ferramenta WHOQOL, abordando os domínios Físico, Psicológico, Relaçóes Sociais, Meio Ambiente e Qualidade de Vida, conforme proposto pela Organização Mundial de Saúde.

$\mathrm{O}$ indivíduo pesquisado é solicitado a fazer uma reflexão sobre as duas últimas semanas de sua vida e avalie como se sente em relação à sua qualidade de vida, tendo em 
mente seus valores, aspiraçóes, prazeres e preocupaçóes, devendo assinalar somente uma das cinco alternativas apresentadas para cada uma das questóes (FLECK, 2000).

O WHOQOL-bref é composto por questôes autoaplicáveis e aborda a percepção dos sujeitos em seu contexto, na sua cultura e seus valores sobre sua qualidade de vida (WHOQOL, 1998) (TABELA 2).

Tabela 2 - Parâmetros de avaliação da sustentabilidade social

\begin{tabular}{|c|c|c|c|}
\hline Parâmetro & $\begin{array}{c}\text { Pontuaçáo máxima } \\
\text { possível }\end{array}$ & Itens avaliados & $\%$ \\
\hline Domínio Físico & 27 & $\begin{array}{l}\text { Dor e desconforto } \\
\text { Energia e Fadiga } \\
\text { Sono e Repouso } \\
\text { Mobilidade } \\
\text { Atividades da vida cotidiana } \\
\text { Dependência de medicação ou } \\
\text { tratamento } \\
\text { Capacidade de trabalho }\end{array}$ & 20 \\
\hline Domínio Psicológico & 26 & $\begin{array}{l}\text { Sentimentos positivos } \\
\text { Pensar e aprender } \\
\text { Memória e concentração } \\
\text { Imagem corporal e aparência } \\
\text { Sentimentos negativos } \\
\text { Crenças pessoais }\end{array}$ & 20 \\
\hline Domínio Social & 15 & $\begin{array}{l}\text { Relaçóes pessoais } \\
\text { Suporte social } \\
\text { Atividade sexual }\end{array}$ & 20 \\
\hline Domínio Ambiental & 35 & $\begin{array}{l}\text { Segurança física e proteção } \\
\text { Ambiente no lar } \\
\text { Recursos financeiros } \\
\text { Cuidados de saúde } \\
\text { Disponibilidade social e qualidade } \\
\text { Oportunidade de conseguir novas } \\
\text { informaçóes e habilidades } \\
\text { Participação e oportunidades de } \\
\text { recreação e lazer } \\
\text { Ambiente físico (poluição, ruído, } \\
\text { trânsito e clima) e transporte }\end{array}$ & 20 \\
\hline Qualidade de vida & 20 & Qualidade de vida & 20 \\
\hline Totais & - & - & 100 \\
\hline
\end{tabular}

Fonte: Adaptado de Fleck (2000)

Para o contexto ambiental são relacionados os parâmetros Dejetos; Água; APP; Reserva Legal; Agrotóxicos e Fertilizantes; Declividade; Erosão; Queimadas e Usos de terra (TABELA 3). 
Tabela 3 - Parâmetros de avaliação da sustentabilidade ambiental

\begin{tabular}{|c|c|c|c|c|}
\hline Parâmetro & Pontuaçáo & Sub-parâmetro & Pontuaçáo & $\%$ \\
\hline \multirow{3}{*}{ Dejetos } & \multirow{3}{*}{20} & Armazenamento do dejeto sólido & 10 & \multirow{3}{*}{20} \\
\hline & & Armazenamento do dejeto líquido & 5 & \\
\hline & & Destinação do dejeto animal & 5 & \\
\hline \multirow{2}{*}{ Água } & \multirow{2}{*}{10} & Fonte de água para consumo animal & 5 & \multirow{2}{*}{10} \\
\hline & & Fonte de água para consumo humano & 5 & \\
\hline \multirow{2}{*}{ APP } & \multirow{2}{*}{15} & Percentual de utilização das APP's & 10 & \multirow{2}{*}{15} \\
\hline & & Uso predominante na APP & 5 & \\
\hline Reserva Legal & 10 & $\begin{array}{c}\text { Percentual de vegetação nativa para averbação } \\
\text { em reserva legal }\end{array}$ & 10 & 10 \\
\hline \multirow{2}{*}{$\begin{array}{l}\text { Agrotóxicos e } \\
\text { Fertilizantes }\end{array}$} & \multirow{2}{*}{15} & $\begin{array}{c}\text { Utilizaçáo de Fertilizantes químicos e } \\
\text { agrotóxicos }\end{array}$ & 10 & \multirow{2}{*}{15} \\
\hline & & Armazenamento de embalagens de agrotóxicos & 5 & \\
\hline Declividade & 10 & Declividade do terreno & 10 & 10 \\
\hline Erosão & 5 & Evidências de solo erodido & 5 & 5 \\
\hline Queimadas & 5 & Evidências de queimadas & 5 & 5 \\
\hline Usos de terra & 10 & Diversidade de coberturas & 10 & 10 \\
\hline Totais & - & - & 100 & 100 \\
\hline
\end{tabular}

Fonte: Adaptado de Rempel et al. (2012).

Os 23 indicadores de sustentabilidade são calculados segundo informaçóes levantadas a partir de um questionário aplicado. Estes valores são obtidos apoiados em funçóes que atribuem valor às variáveis, através de fatores de ponderação para cada parâmetro avaliado. Ao final geram-se índices de zero (0) a um (1), sendo o valor sessenta $(0,60)$ definido como limiar de sustentabilidade ou valor de referência correspondente ao bom desempenho ambiental, econômico e social (TABELA 4).

Tabela 4 - Conceitos de sustentabilidade e respectivos índices

\begin{tabular}{|l|l|c|}
\hline Conceito & Índice de Sustentabilidade & Índice \\
\hline Excelente & Pontuação igual ou maior que 80 & $\mathbf{1 , 0 0}$ \\
\hline Bom & Pontuação igual ou maior que 60 & $\mathbf{0 , 8 0}$ \\
\hline Regular & Pontuação igual ou maior que 40 & $\mathbf{0 , 6 0}$ \\
\hline Ruim & Pontuação igual ou maior que 20 & $\mathbf{0 , 4 0}$ \\
\hline Inadequada & Pontuação menor que 20 & $\mathbf{0 , 2 0}$ \\
\hline
\end{tabular}

Fonte: Elaborado pelos autores (2016). 
Utilizando a Escala Likert para classificação dos valores de sustentabilidade, convencionou-se expressar cinco (5) níveis: Inadequada $(0 \mathrm{~F} 0,20)$, Ruim $(0,20 \mathrm{~F} 0,40)$, Regular $(0,40 \mathrm{~F} 0,60)$, Bom $(0,60 \mathrm{~F} 0,80)$, Excelente $(0,80 \mathrm{~F}$ 1,00). Cada nível por sua vez está representado com uma coloração correspondente, o que facilita visualizar os resultados de forma mais didática.

Os índices de sustentabilidade são construídos a partir dos dados agregados das dimensões utilizadas nas planilhas, sendo formados pela composição das partes das dimensões e expressam a proximidade que o sistema está de uma situação ideal de sustentabilidade. Desta forma quanto mais próximo do limiar, melhor o grau de sustentabilidade.

Verona (2008) observa que a condição ruim ou inadequada, não representa que o agroecossistema não esteja em condiçóes de reverter o processo em que se encontra, mas indica que quanto mais próximo deste nível maior é a dificuldade de alcançar bons resultados quanto aos parâmetros avaliados. Portanto o valor 0,60 foi definido como a situação que é minimamente esperada pelo estabelecimento rural.

Por outro lado, a condição bom ou excelente - desejável, não indica que a situação do agroecossistema não possa ser melhorada, mas representa que quanto mais próxima deste valor, melhores são as suas condiçóes dentro do aspecto estudado (VERONA, 2008).

\section{4 Área de estudo}

Para validação do método, a proposta foi aplicada em cinco propriedades produtoras de leite no município de Teutônia, no Vale do Taquari, Rio Grande do Sul, as quais estão vinculadas à pesquisa denominada "Sustentabilidade ambiental em propriedades produtoras de leite do Vale do Taquari”, do Centro Universitário UNIVATES, que forneceu dados para o desenvolvimento do presente trabalho.

A região do Vale do Taquari é hoje uma das maiores produtoras de leite do Rio Grande do Sul, com um total de 360 milhóes de litros/leite/ano, é a terceira maior bacia leiteira do Estado, demonstrando ser uma alternativa viável para manter a viabilidade econômica das pequenas propriedades, consistindo-se numa das principais atividades econômicas da regiâo (IBGE, 2012).

Em 2012, os três municípios com maior produção leiteira na regiáo do Vale do Taquari, são Estrela (37.950 mil litros/ano), Teutônia (35.550 mil litros/ano) e Arroio do Meio (25.500 mil litros). Destacando que, juntos, estes três municípios produziram um total de quase 100 milhóes de litros de leite, correspondendo a quase um terço da produção leiteira do Vale (IBGE, 2012).

A produção média por vaca no Vale do Taquari é 9,2 litros/vaca/dia (no estado do RS a média de 7,3 litros), sendo que Estrela registra em torno de 13,5 litros/vaca/dia, Teutônia 12,2 litros/vaca/dia e Arroio do Meio fica em 9,4 litros/vaca/dia (IBGE 2012).

O município de Teutônia possui uma circunscrição territorial de $179,17 \mathrm{~km}^{2}$. Está localizado na região do Vale do Taquari, mais precisamente na encosta inferior do Nordeste. Suas coordenadas geográficas são: 5147'57” W de longitude; 29²6’36” S de latitude (TEUTÔNIA, 2015). 
Teutônia possui características de minifúndio, onde a média entre as propriedades é de 8,8 hectares, contabilizando cerca de 650 produtores de leite que somam aproximadamente $13 \%$ de participação no Valor Adicionado Bruto (VAB) da agropecuária no município (TEUTÔNIA, 2015).

Observou-se que os agroecossistemas avaliados possuem características em comum como: áreas com uma intensa ação no que se refere à exploração dos recursos naturais; possuem as mesmas oportunidades para alcançarem os planos propostos pelo governo e agricultura com base familiar. Por outro lado, verificou-se a presença de diferenças entre agroecossistemas que devem ser respeitadas, quanto às características locais, seja de microclima, vegetação e aspectos culturais.

Assim, o Vale do Taquari, particularmente também o município de Teutônia, vive um dilema em relação ao padrão de desenvolvimento de sua pecuária leiteira. De um lado, a busca para atender os mercados externos, cada vez mais exigentes e competitivos, demanda uma produção cada vez mais especializada e intensiva. Por outro lado, a ausência de práticas ambientais adequadas de manejo das propriedades rurais e da própria atividade leiteira, principalmente com relação aos dejetos bovinos, resulta em expressivos impactos ambientais (REMPEL et al., 2012).

\subsection{Coleta de Dados}

A pesquisa foi realizada durante o mês de junho de 2015, a partir do contato com a Secretaria da Agricultura de Teutônia e depois com a Empresa de Assistência Técnica e Extensão Rural - Emater - do município, para apresentação da proposta da pesquisa e para que os mesmos indicassem quais propriedades seriam avaliadas.

A partir da aplicação dos questionários obtiveram-se os resultados quantitativos dos impactos e os índices parciais e agregados de impacto da tecnologia selecionada, expressos graficamente em resultados de sustentabilidade diagnosticados.

Junto à entrevista e à anotação das condiçóes observadas nos parâmetros analisados, foi feita a realização do levantamento de campo, com uma caminhada pelo estabelecimento para conhecê-lo e identificar junto com o produtor os tipos de usos da terra, sendo estes demarcados em um mapa da propriedade já impresso anteriormente pelo grupo de pesquisa. Durante as atividades em campo, realizou-se aferição das coordenadas UTM com um GPS, para exatidão das demarcaçóes realizadas na imagem via satélite da propriedade.

Após as entrevistas, os dados foram sistematizados e apresentados em dois formatos. Os gráficos do tipo radar apontaram a variação dos indicadores dentro de cada uma das três dimensões da sustentabilidade, e, os índices de sustentabilidade, que são fatores construídos a partir dos dados agregados de todos os indicadores.

A partir destes resultados visuais é possível discutir-se a indicação de alternativas de manejo que permita minimizar os impactos negativos e potencializar os impactos positivos, contribuindo para o desenvolvimento local sustentável. A análise da propriedade em primeiro momento permite auxiliar cada produtor conforme os pontos específicos que merecerem maior atenção. 
Ao final, o produtor recebe como retorno, a avaliação completa do seu estabelecimento rural: mapa com a delimitação e tamanho dos usos de sua propriedade bem como o resultado que ela apresentou quanto à sustentabilidade em suas três dimensóes e, se for o caso, em quais quesitos ela pode sofrer modificaçóes para obter uma melhoria.

Por questôes éticas serão usados números para identificação dos participantes da pesquisa, como forma de manter em sigilo as informaçóes particulares prestadas pelos produtores, identificando-os como Produtor 01, Produtor 02, até Produtor 05.

\section{RESULTADOS E DISCUSSÁO}

Como forma de demonstração da avaliação realizada por meio do sistema desenvolvido, são apresentados os dados do produtor 1. Após são caracterizados os agroecossistemas da cidade de Teutônia e discutidos aspectos relacionados as cinco propriedades avaliadas. Durante a análise são demonstradas algumas características e funcionalidades do sistema de indicadores.

Para os parâmetros econômicos (TABELA 5), a propriedade leiteira do Produtor 01 ficou com índice de sustentabilidade em 0,88 , considerado excelente, portanto. Os indicadores com melhor desempenho foram grau de endividamento e sucessão familiar, além do acesso a serviços básicos, que também ficou muito bem pontuado.

Tabela 5 - Parâmetros de sustentabilidade econômica

\begin{tabular}{|c|c|c|c|c|c|}
\hline Parâmetro & Pontuaçáo & Subparâmetro & Resultado & Total & Índice \\
\hline \multirow{4}{*}{ Produtividade e Renda } & 5 & Capacidade de produção e renda bruta & 3,8 & \multirow{4}{*}{88} & \multirow{4}{*}{0,88} \\
\hline & 5 & Relação custo/benefício da atividade & 3,8 & & \\
\hline & 5 & Pretensão para os próximos anos & 5 & & \\
\hline & 5 & Satisfação com a renda & 5 & & \\
\hline Diversificação da renda & 10 & Principais fontes de renda e participação & 8,8 & 88 & 0,88 \\
\hline Evoluçấo patrimonial & 10 & Evoluçâo patrimonial do imóvel rural & 7,5 & 75 & 0,75 \\
\hline Grau de endividamento & 10 & Valor da dívida em relação a renda & 10,0 & 100 & 1,00 \\
\hline Serviços Básicos & 10 & Serviços básicos disponíveis na residência & 9,8 & 98 & 0,98 \\
\hline Escolaridade e capacitação & 10 & Escolaridade e capacitação para a atividade & 9,0 & 90 & 0,90 \\
\hline Evolução tecnológica & 10 & Evolução tecnológica & 7,8 & 78 & 0,78 \\
\hline Gestão do empreendimento & 10 & Gestão do empreendimento & 7,3 & 73 & 0,73 \\
\hline Sucessão familiar & 10 & Sucessão familiar & 10,0 & 10,0 & 1,00 \\
\hline \multicolumn{3}{|c|}{ SUSTENTABILIDADE ECONÔMICA } & - & 88 & 0,88 \\
\hline
\end{tabular}

Fonte: Elaborado pelos autores (2016).

Estudo realizado por Cyrne (2016), verificando um sistema de indicadores de gestão em propriedades produtoras de leite no Vale do Taquari, também utilizou Teutônia como 
estudo de caso e concluiu que o painel de indicadores utilizados, com os mesmos parâmetros do trabalho aqui proposto, constituiu oportunidade de melhoria para o gerenciamento das propriedades produtoras de leite no Vale do Taquari e também na Galícia.

Os resultados em relaçáo ao Produtor 01, conforme Tabela 6, indicam que o índice de sustentabilidade da dimensão ambiental ficou em 0,81 , indicando que a propriedade está, em relação aos parâmetros avaliados, em condiçôes ambientais com nível considerado excelente. Os indicadores com melhor desempenho foram água, reserva legal, erosão, queimadas e usos de terra e dejetos foi o item com menor valoração (regular).

Tabela 6: Parâmetros de sustentabilidade ambiental

\begin{tabular}{|c|c|c|c|c|c|}
\hline Parâmetro & Pontuaçáo & Subparâmetro & Resultado & Total & Índice \\
\hline \multirow{3}{*}{ Dejetos } & 10 & Armazenamento do dejeto sólido & 7,50 & \multirow{3}{*}{56} & \multirow{3}{*}{0,56} \\
\hline & 5 & Armazenamento do dejeto líquido & 2,50 & & \\
\hline & 5 & Destinação do dejeto animal & 1,25 & & \\
\hline \multirow{2}{*}{ Água } & 5 & Fonte de água para consumo animal & 5,00 & \multirow{2}{*}{100} & \multirow{2}{*}{1,00} \\
\hline & 5 & Fonte de água para consumo humano & 5,00 & & \\
\hline \multirow{2}{*}{ APP } & 10 & Percentual de utilização das APPs & 7,50 & \multirow{2}{*}{75} & \multirow{2}{*}{0,75} \\
\hline & 5 & Uso predominante na APP & 3,75 & & \\
\hline Reserva Legal & 10 & $\begin{array}{l}\text { Percentual de vegetação nativa para averbação em } \\
\text { reserva legal }\end{array}$ & 10,00 & 100 & 1,00 \\
\hline \multirow{2}{*}{$\begin{array}{l}\text { Agrotóxicos e } \\
\text { Fertilizantes }\end{array}$} & 10 & Utilizaçấo de fertilizantes químicos e agrotóxicos & 7,50 & \multirow{2}{*}{75} & \multirow{2}{*}{0,75} \\
\hline & 5 & Armazenamento de embalagens de agrotóxicos & 3,75 & & \\
\hline Declividade & 10 & Declividade do terreno & 7,50 & 75 & 0,75 \\
\hline Erosão & 5 & Evidência de solo erodido & 5,00 & 100 & 1,00 \\
\hline Queimadas & 5 & Evidências de queimadas & 5,00 & 100 & 1,00 \\
\hline Uso da terra & 10 & Diversidade de coberturas & 10,00 & 100 & 1,00 \\
\hline \multicolumn{3}{|c|}{ SUSTENTABILIDADE AMBIENTAL } & - & 88 & 0,88 \\
\hline
\end{tabular}

Fonte: Elaborado pelos autores (2016).

Outros estudos sobre sustentabilidade ambiental realizados na regiáo do Vale do Taquari, utilizando os mesmos parâmetros analisados neste trabalho, demonstram que o índice de sustentabilidade varia bastante de propriedade para propriedade, contudo, é sempre nos parâmetros "dejetos", "uso da terra" e "água" que se encontram as menores pontuaçóes (BORTOLI; REMPEL; BICA, 2014; MARAGNON; REMPEL, 2014; ROLOFF; REMPEL; ECKHARDT, 2014).

Em relaçáo aos indicadores sociais, o sistema indica que o índice de sustentabilidade desta dimensão para Produtor 01, ficou em 0,91, indicando que a qualidade de vida por este produtor é apontada com excelente. Nesta avaliação, os domínios físico, psicológico, relaçóes sociais e meio ambiente foram considerados excelentes, e a parte de qualidade de 
vida, considerando a avaliação da qualidade de vida e a satisfação deste com a sua saúde foram consideradas boas (TABELA 7).

Tabela 7 - Parâmetros de sustentabilidade social

\begin{tabular}{lclccc}
\hline \multicolumn{1}{c}{ Parâmetro } & $\begin{array}{c}\text { Pontuaçáo máxima } \\
\text { possível }\end{array}$ & Itens avaliados & Resultado & Total & Índice \\
\hline Domínio Físico & 20 & Domínio Físico & 20 & 100 & 1,00 \\
\hline Domínio Psicológico & 20 & Domínio Psicológico & 19 & 92 & 0,92 \\
\hline Domínio Social & 20 & Domínio Social & 20 & 100 & 1,00 \\
\hline Domínio Ambiental & 20 & Domínio Ambiental & 18 & 88 & 0,88 \\
\hline Qualidade de vida & 20 & Qualidade de vida & 16 & 75 & 0,75 \\
\hline SUSTENTABILIDADE AMBIENTAL & & & $\mathbf{9 1}$ & $\mathbf{0 , 9 1}$ \\
\hline
\end{tabular}

Fonte: Elaborado pelos autores (2016).

Vários estudos sobre a qualidade de vida dos produtores do Vale do Taquari foram desenvolvidos, contudo, com produtores rurais destaca-se o estudo de Rempel, Haetinger e Sehnem (2013), realizado com idosos de Teutônia, que atribuem ao trabalho rural possíveis queixas de dor, bem como reflexos do trabalho em sua postura física. Cavalheiro et al. (2014) analisou o perfil socioeconômico e a qualidade de vida de produtores de leite da Comunidade São Justino, em Juína, utilizando o Whoqol-Bref e concluíram que os produtores que trabalham em comunidade, consideram a sua qualidade de vida boa, com ênfase aos aspectos sociais.

Além do índice de sustentabilidade, que são fatores construídos a partir dos dados agregados de todos os indicadores, os resultados de cada dimensão são expressos através de gráficos de radar preenchido, que apontam a variação dos indicadores de sustentabilidade (GRÁFICO 1), permitindo comparar os valores agregados de várias séries de dados. 


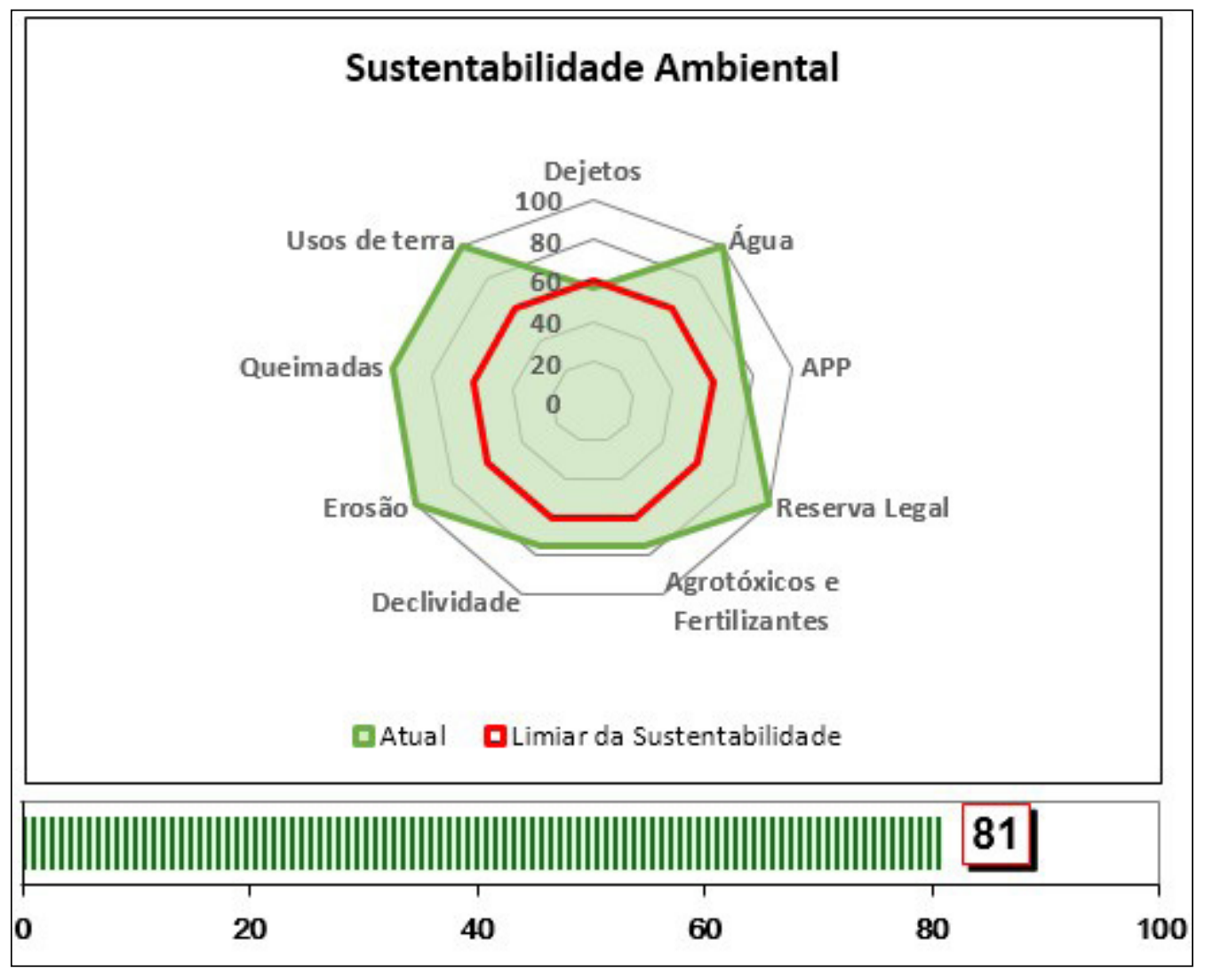

Fonte: Elaborado pelos autores (2016).

O próximo gráfico (GRÁFICO 2), mostra os 23 indicadores avaliados pelo sistema de forma integrada, distribuídos nas três dimensôes, mostrando o valor final de índice em cada um dos aspectos, bem como o índice final do estabelecimento do Produtor $01 \mathrm{em}$ 0,87 , considerado excelente. Novamente, igualmente neste gráfico, fica destacado a menor valoração em relação ao parâmetro dejetos, indicando este como prioridade para melhorar a condição ambiental do estabelecimento.

De forma geral, a propriedade apresentou um excelente desempenho socioeconômico e ambiental. Algumas recomendaçóes como adequaçóes quando ao manejo dos dejetos, maior preservação das áreas de APP's, busca por alternativas de defensivos agrícolas menos poluentes, manejo mais conservacionista dos solos, investimentos em infraestrutura e gestáo do empreendimento são fundamentais para a manutenção e melhoria da sustentabilidade da propriedade. 
Gráfico 2 - Parâmetros avaliados e índice final de sustentabilidade

\begin{tabular}{|c|c|c|c|c|c|}
\hline \multirow[t]{2}{*}{100,00} & \multirow{2}{*}{87} & & TOTAL DE INDICADORES AVALIADOS & 23 & \\
\hline & & & ÍNDICE DE SUSTENTABILIADADE & 0,87 & \\
\hline \multirow{7}{*}{80,00} & & \multirow{10}{*}{ 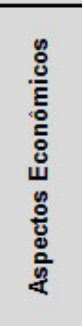 } & Produtividade e renda & 0,88 & \\
\hline & & & Diversificação da renda & 0,88 & \\
\hline & & & Evolução patrimonial & 0,75 & 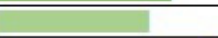 \\
\hline & & & Grau de endividamento & 1,00 & \\
\hline & & & Servicos básicos & 0,98 & \\
\hline & & & Escolaridade e capacitação & 0,90 & \\
\hline & & & Evolução tecnológica & 0,78 & \\
\hline \multirow{6}{*}{60,00} & & & Gestão do empreendimento & 0,73 & 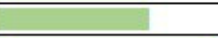 \\
\hline & & & Sucessão familiar & 1,00 & \\
\hline & & & SUBTOTAL ECONÔMICO & 0,88 & \\
\hline & & & Domínio Físico & 1,00 & \\
\hline & & & Domínio Psicológico & 0,92 & \\
\hline & & $\stackrel{800}{\pi} \cdot \frac{0}{\pi}$ & Domínio Relaç̃es Sociais & 1,00 & \\
\hline \multirow{6}{*}{40,00} & & $\varpi \bar{\circ}$ & Domínio Meio Ambiente & 0,88 & \\
\hline & & & \begin{tabular}{|l|} 
Qualidade de Vida \\
\end{tabular} & 0,75 & \\
\hline & & & SUBTOTAL SOCIAL & 0,91 & \\
\hline & & & Dejetos & 0,56 & \\
\hline & & & Áqua & 1,00 & \\
\hline & & & APP & 0,75 & \\
\hline \multirow{7}{*}{20,00} & &.$\overline{0}$ & Reserva Legal & 1,00 & \\
\hline & & है & Aqrotóxicos e Fertilizantes & 0,75 & \\
\hline & & 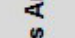 & Declividade & 0,75 & 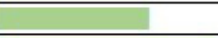 \\
\hline & & 잉 & Erosão & 1,00 & \\
\hline & & $\nsubseteq$ & Queimadas & 1,00 & \\
\hline & & 4 & Usos de terra & 1,00 & \\
\hline & & & SUBTOTAL AMBIENTAL & 0,81 & \\
\hline
\end{tabular}

Fonte: Elaborado pelos autores (2016).

O Gráfico 3 mostra os índices de sustentabilidade de cada um dos estabelecimentos avaliados, através de um gráfico radar. Pode-se observar que o sistema melhor avaliado foi o do Produtor 01 (0,87 - excelente) e com menor nota global foi o do Produtor 05 (0,70 bom), sendo que todos ficaram acima do limiar de sustentabilidade $(0,60)$. 
Gráfico 3 - Índices de sustentabilidade das propriedades avaliadas

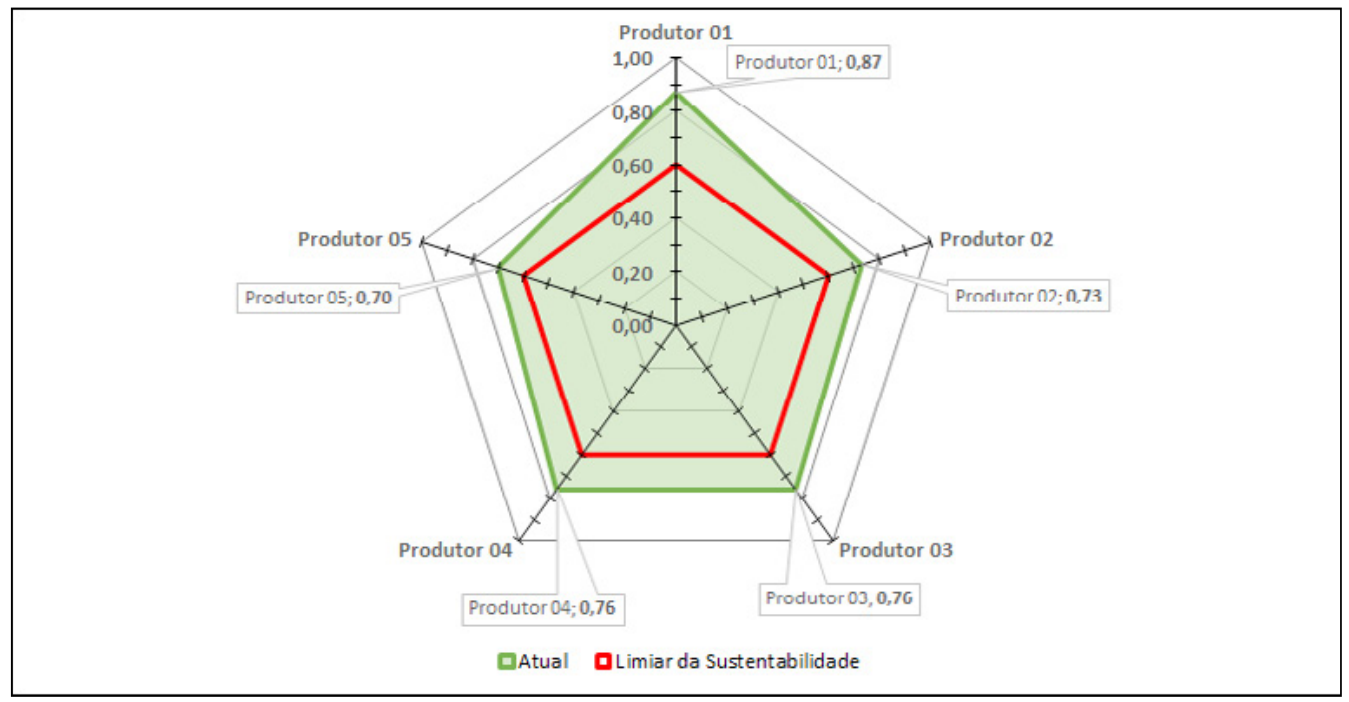

Fonte: Elaborado pelos autores (2016).

$\mathrm{Na}$ análise a partir da Figura 3, pode-se observar que o índice quantitativo de sustentabilidade médio da amostra, considerando as cinco propriedades, foi 0,76, caracterizando as propriedades produtoras de leite do município de Teutônia como propriedades boas, de acordo com o índice qualitativo.

Novamente se observa que propriedade melhor avaliada, de forma global, foi a do Produtor 01, com grau de sustentabilidade final 0,87, considerado como desempenho excelente. $\mathrm{E}$ a propriedade com a menor média global foi a quinta propriedade, com índice 0,70 , considerado bom, mas que se encontra próximo ao limiar de sustentabilidade, o que mostra que alguns indicadores demonstram fragilidades que precisam ser melhoradas.

Considerando o contexto econômico, em média, nenhum parâmetro ficou abaixo do conceito bom. Ficaram com desempenho ruim os indicadores econômicos da quinta propriedade, evolução do patrimônio e sucessão familiar. O Produtor 05 também demonstra descontentamento com relação a produtividade e renda geradas no estabelecimento. Para o Produtor 03 acabam sendo destaques negativos os parâmetros evoluçáo tecnológica e a sucessão familiar e para o Produtor 02 a opção grau de endividamento. 
Figura 3 - Parâmetros avaliados e índice final de sustentabilidade das cinco propriedades

\begin{tabular}{|c|c|c|c|c|c|c|}
\hline \multirow{3}{*}{$\begin{array}{c}\text { ÍNDICE DE } \\
\text { SUSTENTABILIADADE }\end{array}$} & Produtor 01 & Produtor 02 & Produtor 03 & Produtor 04 & Produtor 05 & MÉDIA \\
\hline & Excelente & Bom & Bom & Bom & Bom & Bom \\
\hline & 0,87 & 0,73 & 0,76 & 0,76 & 0,70 & 0,76 \\
\hline Produtividade e renda & 88 & 75 & 81 & 69 & 50 & 73 \\
\hline Diversificaçäo da renda & 88 & 71 & 83 & 78 & 85 & 81 \\
\hline Evolução patrimonial & 75 & 100 & 75 & 100 & 25 & 75 \\
\hline Grau de endividamento & 100 & 50 & 75 & 75 & 75 & 75 \\
\hline Serviços básicos & 98 & 95 & 83 & 68 & 70 & 83 \\
\hline Escolaridade e capacitação & 90 & 92 & 75 & 75 & 80 & 82 \\
\hline Evoluçäo tecnológıca & 78 & 93 & 50 & 75 & 65 & 72 \\
\hline Gestäo do empreendimento & 73 & 80 & 75 & 80 & 63 & 74 \\
\hline Sucessão familiar & 100 & 100 & 50 & 75 & 25 & 70 \\
\hline SUBTOTAL ECONŌMICO & 88 & 83 & 73 & 74 & 59 & 75 \\
\hline Dominio Fisıco & 100 & 71 & 79 & 89 & 93 & 86 \\
\hline Dominio Psicológico & 92 & 63 & 71 & 71 & 79 & 75 \\
\hline Domínio Relações Sociais & 100 & 75 & 83 & 75 & 100 & 87 \\
\hline Dominıo Mcıo Ambicntc & 88 & 59 & 59 & 69 & 84 & 72 \\
\hline Qualidade de Vida & 75 & 63 & 75 & 88 & 100 & 80 \\
\hline \begin{tabular}{|c|} 
SUBTOTAL SOCIAL \\
\end{tabular} & 91 & 66 & 73 & 78 & 91 & 80 \\
\hline Dejetos & 56 & 75 & 56 & 56 & 25 & 54 \\
\hline Água & 100 & 100 & 100 & 88 & 75 & 93 \\
\hline APP & 75 & 67 & 75 & 100 & 67 & 77 \\
\hline Reserva l egal & 100 & 25 & 100 & 75 & 100 & 80 \\
\hline Agrotóxicos e Fertilizantes & 75 & 58 & 75 & 58 & 75 & 68 \\
\hline Declividade & 75 & 75 & 75 & 75 & 50 & 70 \\
\hline Erosảo & 100 & 100 & 100 & 100 & 50 & 90 \\
\hline Queimadas & 100 & 100 & 100 & 100 & 100 & 100 \\
\hline \begin{tabular}{|l|} 
Usos de terra \\
\end{tabular} & 100 & 50 & 100 & 50 & 50 & 70 \\
\hline \begin{tabular}{|l|} 
SUBTOTAL AMBIENTAL \\
\end{tabular} & 81 & 69 & 81 & 76 & 61 & 74 \\
\hline Excelente 100 & 80 & Regular & Ruim & 40 & Inadequ & 20 \\
\hline
\end{tabular}

Fonte: Elaborado pelos autores (2016).

Quanto aos parâmetros sociais, também, na média, todos os indicadores ficaram com conceitos bom ou excelente. Para o Produtor 02 e Produtor 03, o domínio meio ambiente acabou com a menor pontuação, demonstrando alguns descontentamentos associadas a algumas particularidades em relação a sua qualidade de vida.

No quesito ambiental, chama grande atenção a questão dos dejetos, sendo que a média geral ficou como regular (54). Em uma das propriedades, o indicador ficou com o conceito ruim, três com conceito regular e um bom. Cabe destacar ainda que este é, de todos os indicadores, o mais preocupante entre aos resultados expressos.

Além destes, a reserva legal ficou com conceito ruim para o Produtor 02, agrotóxicos e fertilizantes ficam qualificados como regular para os produtores 02 e 04 , declividade e erosão são avaliados como regular para o produtor 05 e a quantidade de coberturas é o ponto com baixas notas para os produtores 02,04 e 05 .

\section{CONSIDERAÇÓES FINAIS}

O sistema de indicadores para avaliação da sustentabilidade de propriedades produtoras de leite aqui proposto, com o objetivo de analisar a perspectiva do desenvolvimento rural sustentável, por meio de um sistema de indicadores para avaliação da sustentabilidade de propriedades produtoras de leite considerou as dimensóes econômico, social e ambiental. 
Este sistema mostrou-se um método adequado e suficiente para aplicação em campo para avaliação do impacto de atividades agropecuárias.

Quanto ao primeiro objetivo específico o sistema permitiu caracterizar e validar a estrutura e o funcionamento de uma planilha de significância aplicada ao processo de planejamento sob a perspectiva do desenvolvimento sustentável. Conforme mencionado, a ferramenta tem simples aplicação e permite expressar os resultados na forma de relatórios e gráficos de fácil manuseio, permitindo um diagnóstico inicial das práticas realizadas na propriedade e avaliando a sustentabilidade dessas atividades, contemplando o quarto objetivo específico.

Desta forma, o sistema permite verificar as características gerais das propriedades produtoras de leite, considerando aspectos do âmbito econômico, social e ambiental, estabelecido nesta pesquisa como o segundo objetivo específico, e a partir daí será possível determinar a situação ambiental das propriedades e, se necessário, sugerir mudanças que auxiliem o produtor a tornar a atividade mais sustentável, atendendo ao terceiro objetivo específico.

O sistema pode ser utilizado tanto de forma individual, para um único produtor que deseja fazer um diagnóstico da sustentabilidade de suas atividades, quanto para realização de uma avaliação em escala maior, sendo aplicada a uma comunidade, cidade ou mesmo regiōes maiores, permitindo um diagnóstico facilitado da sustentabilidade nestes contextos.

Além disso, os resultados obtidos mediante a análise dos indicadores permitem concluir que, no geral, os sistemas produtivos desenvolvidos pelos produtores de Teutônia sugerem que os mesmos estão adequados nos aspectos socioeconômicos e ambientais. Mas a percepção que se tem é de que os produtores rurais só priorizam aspectos ambientais, adotando práticas direcionadas ao uso correto dos recursos naturais, quando estes interferem diretamente nos resultados econômicos da atividade.

De todos os indicadores avaliados, dejetos foi o parâmetro com mais baixa avaliação, ficando na média abaixo do limiar de sustentabilidade nas propriedades pesquisadas, o que indica que possa resultar em expressivos impactos ambientais nestes estabelecimentos e nas comunidades locais, indicando este como prioridade para melhorar a condição ambiental destas propriedades.

Pode-se concluir, portanto, que fatores sociais, meio ambiente e desenvolvimento não constituem desafios separados, mas estão inevitavelmente interligados. Em outras palavras, o desenvolvimento não se mantém se a base de recursos ambientais se deteriora; o meio ambiente não pode ser protegido se o crescimento não leva em conta as consequências da destruição ambiental.

Como limitaçóes do método aqui proposto pode-se indicar a necessidade de geração de uma série histórica, permitindo a replicação dos questionários e assim fazer o levantamento de informaçóes em diferentes períodos, e, a partir desta análise, oferecer recursos de monitoramento dos indicadores desejados, ao longo do tempo. Trabalhos futuros também podem contemplar a verificação de lacunas e outras melhorias na ferramenta apresentada.

Finalmente, a preocupação com os indicativos da sustentabilidade dos sistemas leva a um olhar mais atento da realidade das propriedades produtoras de leite, e também a 
um entendimento mais amplo do desenvolvimento rural. Nesta perspectiva, devem-se considerar outros aspectos além da produtividade econômica de um determinado sistema. O desafio colocado é o de internalizar e evidenciar a diversidade, em todas as suas dimensóes, e procurar soluçóes e propostas que contribuam de forma efetiva para a valorização da Vida.

\section{REFERÊNCIAS}

BARBIERI, J. C.; CAJAZEIRA, J. E. R. Responsabilidade social empresarial e empresa sustentável: da teoria à prática. Sáo Paulo: Saraiva, 2009.

BELLEN, H. M. van. Indicadores de sustentabilidade: uma análise comparativa. 2. ed. Rio de Janeiro: FGV, 2010.

BORTOLI, J.; REMPEL, C.; BICA, J. B. Sustentabilidade ambiental de propriedades leiteiras localizadas em floresta ombrófila mistra e em floresta estacional decidual, no Vale do Taquari/RS. RGSN - Revista Gestáo, Sustentabilidade e Negócios, Canoas, v. 2,p. 146-163, 2014.

BUAINAIN, A. M.; ROMEIRO, A. R. A agricultura familiar no Brasil: agricultura familiar e sistemas de produçâo. Brasília, DF: Incra, 2000.

CAVALHEIRO, C. N.; REMPEL, C.; LAROQUE, L. F. S.; MACHADO, B. N. B. Perfil socioeconômico e análise da qualidade de vida dos produtores de leite da Comunidade São Justino em Juína/MT. Destaques Acadêmicos, Lajeado, v. 6, n. 3, p. 148-156, 2014.

COSTA, Z. F.; BUENO, O. C. Eficiência energética e econômica da produção de leite bovino em exploraçóes familiares no município de Pardinho, região de Botucatu, SP.

Revista Energia na Agricultura, Botucatu, v. 26, n. 1, p. 126-140, 2011.

CMMAD, Comissão Mundial sobre Meio Ambiente e Desenvolvimento. Nosso futuro comum. 2. ed. Rio de Janeiro: Fundação Getúlio Vargas, 1991.

CYRNE, C. C. S. Indicadores de gestáo em propriedades produtoras de leite do Vale do Taquari - $\mathrm{RS}$ - um estudo comparativo com as propriedades da regiáo da Galícia - Espanha. 2015. Tese (Doutorado) - Curso de Ambiente e Desenvolvimento, Centro Universitário UNIVATES, Lajeado, 18 set 2015.

DEPONTI, C. M.; ECKERT, C.; AZAMBUJA, J. L. B. Estratégia para construção de indicadores para avaliação da sustentabilidade e monitoramento de sistemas.

Agroecologia e Desenvolvimento Rural Sustentável, Porto Alegre, v.3, n.4, p.44-52, 2002.

DI DOMENICO, D. et al. Índice de sustentabilidade ambiental na produção leiteira. RACE, Joaçaba, v. 16, n. 4, p. 261-282, 2017 
FERREIRA, J. M. L. et al. Indicadores de Sustentabilidade em Agroecossistemas. Informe Agropecuário, Belo Horizonte, v. 33, n. 271, p. 12-25, 2012.

FLECK, M. P. A. O instrumento de avaliaçáo de qualidade de vida da Organizaçáo Mundial da Saúde (WHOQOL-100): características e perspectivas. Revista Ciência e Saúde Coletiva [online], v. 5, n. 1, p. 33-38, 2000. Disponível em: <http://www.scielo.br/ pdf/csc/v5n1/7077.pdf>. Acesso em: agosto, 2015.

GLIESSMAN, S. R. Agroecologia: processos ecológicos em agricultura sustentável. 2a ed. Porto Alegre, RS: Ed. Universidade/UFRGS, 2001.

IBGE. Instituto Brasileiro de Geografia e Estatística: Censo Agropecuário - 2006. Disponível em: <http://www.ibge.gov.br/home/estatistica/economia/agropecuaria/ censoagro/brasil_2006/Brasil_censoagro2006.pdf>. Acesso em: junho, 2015.

IBGE. Instituto Brasileiro de Geografia e Estatística: Produção da Pecuária Municipal: 2012. Disponível em: <http://www.ibge.gov.br/home/estatistica/economia/ppm/2012/ default.shtm>. Acesso em: junho, 2015.

LEFF, E. Discursos Sustentáveis. São Paulo: Cortez, 2010.

MARANGON, L. R.; REMPEL, C. Sustentabilidade ambiental de propriedades produtoras de leite no município de Anta Gorda - RS. RGSN - Revista Gestáo, Sustentabilidade e Negócios, Canoas, v. 2, p. 164-183, 2014.

MARZALL, K.; ALMEIDA, J. Indicadores de sustentabilidade para agroecossistemas: estado da arte, limites e potencialidades de uma nova ferramenta para avaliar o desenvolvimento sustentável. Cadernos de Ciência \& Tecnologia, Brasília, v.17, n.1, p.41- 59, jan./mar. 2000.

MARQUES, J. F.; SKORUPA, L. A.; FERRAZ, J. M. G. Indicadores de sustentabilidade em agroecossistemas. Jaguariúna, SP, Embrapa Meio Ambiente, 2003, $281 \mathrm{p}$.

NORONHA, J. F; LIMA JÚNIOR, A. C. S. Tecnologia de gestão na propriedade leiteira. In: CARVALHO, L. et al. (Ed.). Tecnologia e gestáo na atividade leiteira. Juiz de Fora: Embrapa Gado de Leite, 2005.

REMPEL, C. et al. Proposta Metodológica de Avaliação da Sustentabilidade Ambiental de Propriedades Produtoras de Leite. Santa Cruz do Sul: Tecno-Lógica, v. 16, n. 1, p. 48-55, jan./jun. 2012.

REMPEL, C.; HAETINGER, C.; SEHNEM, E. Reflexões de idosos sobre as relaçóes entre o trabalho rural, problemas de coluna e postura corporal. Estudos Sociedade e Agricultura (UFRJ), Rio de Janeiro, v. 21, p. 289-307, 2013. 
RIBEIRO, A. C. F.; BRITES, R. S.; JUNQUEIRA, A. M. R. Os aspectos ambientais no processo decisório do produtor rural: estudo de caso Núcleo Rural Taquara. Campina Grande: Revista Brasileira de Engenharia Agrícola e Ambiental, v. 10, n. 3, p. 686691, Set. 2006.

RODRIGUES, G. S.; CAMPANHOLA, C.; KITAMURA, P. C. Avaliaçáo de impacto ambiental da inovaçáo tecnológica agropecuária: AMBITEC-AGRO. Jaguariúna: Editora Embrapa Meio Ambiente, 2003. 95p.

ROLOFF, M.; REMPEL, C.; ECKHARDT, R. R. Sustentabilidade ambiental de propriedades leiteiras do município de Paverama - RS. Tecno-Lógica, Santa Cruz do Sul, v. 18 , n. 2, p. 60-68, 2014.

SACHS, I. Estratégias de transição para o século XXI. In: BURSZTYN, M. (Org.) et al. Para Pensar o Desenvolvimento Sustentável. Brasília: Brasiliense, 2004, p.29-56.

SCHNEIDER, S.; NIEDERLE, P. A. Agricultura familiar e teoria social: a diversidade das formas familiares de produção na agricultura. In: FALEIRO, F. G.; FARIAS NETO, A. L. (Orgs.). Savanas: desafios e estratégias para o equilíbrio entre sociedade, agronegócio e recursos naturais. Planaltina: Embrapa Cerrados, 2008, p. 989-1.014.

TEUTÔNIA. Prefeitura Municipal de Teutônia. Site Institucional. Disponível em: $<$ http://www.teutonia.com.br>. Acesso em: julho, 2015.

VERONA, L. A. F. Avaliaçáo de sustentabilidade em agroecossistemas de base familiar e em transiçáo agroecológica na regiáo sul do Rio Grande do Sul. 2008. 193 f. Tese (Programa de Pós-Graduação em Ciências: Produção Vegetal-Doutorado) - Universidade Federal de Pelotas, Pelotas. 2008.

WHOQOL - Versão em Português dos Instrumentos de Avaliação de Qualidade de Vida (WHOQOL). 1998. Disponível em: <http://www.ufrgs.br/psiquiatria/psiq/whoqol. html>. Acesso em: março, 2015.

YAMAGUCHI, L. C. T.; MARTINS, P. C.; OLIVEIRA, A. F. Gestão da informação como fator de competitividade na produção de leite. In: CARVALHO, L. et al. (Ed.). Tecnologia e gestáo na atividade leiteira. Juiz de Fora: Embrapa Gado de Leite, 2005. 